\title{
Associations of $\mathrm{CT}$ evaluations of antigravity muscles, emphysema and airway disease with longitudinal outcomes in patients with COPD
}

\section{$\operatorname{AUTHOR}(S):$}

Tanabe, Naoya; Sato, Susumu; Tanimura, Kazuya; Oguma, Tsuyoshi; Sato, Atsuyasu; Muro, Shigeo; Hirai, Toyohiro

\section{CITATION:}

Tanabe, Naoya ...[et al]. Associations of CT evaluations of antigravity muscles, emphysema and airway disease with longitudinal outcomes in patients with COPD. Thorax 2021, 76(3): 295-297

\section{ISSUE DATE:}

2021-03

URL:

http://hdl.handle.net/2433/261814

\section{RIGHT:}

(c) Authors (or their employer(s)) 2020. Reuse of this manuscript version (excluding any databases, tables, diagrams, photographs and other images or illustrative material included where a another copyright owner is identified) is permitted strictly pursuant to the terms of the Creative Commons Attribution-Non Commercial 4.0 International (CC-BYNC 4.0) http://creativecommons.org https://creativecommons.org/licenses/by-nc/4.0/.; This is not the published version. Please cite only the published version.; この論文は出版社版でありません。引用の際には出版社版をご確認ざ 利用ください。 


\section{Associations of CT evaluations of antigravity muscles, emphysema, and airway disease with longitudinal outcomes in patients with COPD}

\section{Authors}

Naoya Tanabe ${ }^{1}$, Susumu Sato ${ }^{1 *}$, Kazuya Tanimura $^{1}$, Tsuyoshi Oguma ${ }^{1}$, Atsuyasu Sato ${ }^{1}$, Shigeo Muro ${ }^{2}$, Toyohiro Hirai ${ }^{1}$

\section{Affiliations}

${ }^{1}$ Department of Respiratory Medicine, Graduate School of Medicine, Kyoto University, 54 Kawaharacho, Shogoin, Sakyo-ku, Kyoto, 606-8507, Japan.

${ }^{2}$ Department of Respiratory Medicine, Nara Medical University, 840 Shijo-cho, Kashihara, Nara, 634852, Japan

\section{*Corresponding author}

Susumu Sato, M.D., Ph.D.

Department of Respiratory Medicine, Graduate School of Medicine, Kyoto University, 54 Kawaharacho, Shogoin, Sakyo-ku, Kyoto, 606-8507, Japan

Tel.: +8175 751 3830; Fax: +81 757514643

E-mail: ssato@kuhp.kyoto-u.ac.jp

\section{Abstract (100/100 words)}

Multiple CT indices are associated with disease progression and mortality in COPD patients, but which indices have the strongest association remains unestablished. This longitudinal 10-year observational study ( $\mathrm{n}=247)$ showed that the emphysema severity on CT is more closely associated with the progression of airflow limitation and that a reduction in the cross-sectional area of erector spinae 
muscles $\left(\mathrm{ESM}_{\mathrm{CSA}}\right)$ on $\mathrm{CT}$ is more closely associated with mortality than the other $\mathrm{CT}$ indices, independent of patient demographics and pulmonary function. ESM $_{\mathrm{CSA}}$ is a useful CT index that is more closely associated with long-term mortality than emphysema and airway disease in COPD patients. 


\section{Main manuscript (1000/1000 words), References (10/10)}

Chronic obstructive pulmonary disease (COPD), characterized by airflow limitation, is associated with high morbidity and mortality [1]. Inspiratory chest computed tomography (CT) is used to detect lung cancer and evaluate airway disease, emphysema, and extrapulmonary abnormalities in patients with COPD.

CT studies have shown that emphysema severity, assessed as the low attenuation volume percentage (LAV\%), is associated with the progression of airflow limitation and mortality [1,2]. The fractal dimension of low attenuation clusters (fractal D) that characterizes the heterogeneity in sizes of emphysematous regions is more closely associated with exacerbation than the LAV\% [3]. Regarding airway disease, the wall area percentage (WA\%) is associated with chronic bronchitis symptoms, and the total airway count (TAC) predicts lung function decline [4]; moreover, the airway to lung volume ratio (AWV\%) is associated with airflow limitation and air-trapping, independent of the TAC [5]. The loss of skeletal muscles is an extrapulmonary COPD feature that can be estimated as the reduction in the cross-sectional area of the erector spinae and pectoralis muscles (ESM ${ }_{\text {CSA }}$ and PMCSA $_{\text {C }}$. The

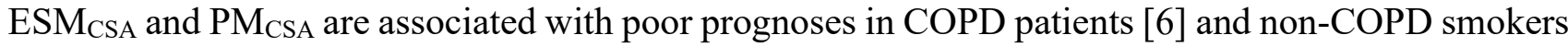
[7], respectively. Nonetheless, which CT indices have relatively stronger associations with disease progression and mortality remains unestablished.

This study analysed data from a single-centre prospective observational study to test whether the ESM $\mathrm{CSA}_{\mathrm{C} A}$ and $\mathrm{PM}_{\mathrm{CSA}}$ affect long-term COPD outcomes more strongly than airway disease and emphysema indices, independent of pulmonary function and demographics that are readily available

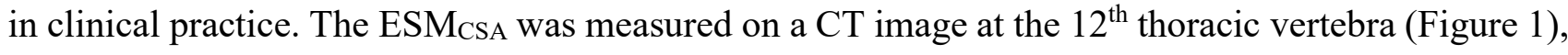
and the PM $\mathrm{CSA}_{\mathrm{C}}$ was measured above the aortic arch [6]. The TAC, WA\% of the segmental bronchus, and AWV\% were calculated to evaluate airway disease $[4,5]$. The LAV\% and fractal D were calculated to evaluate emphysema [3]. To compare the relative impacts of the CT indices on $\mathrm{FEV}_{1}$ decline and 
mortality, the CT indices were normalized by half of their SDs, as previously reported [8]. The

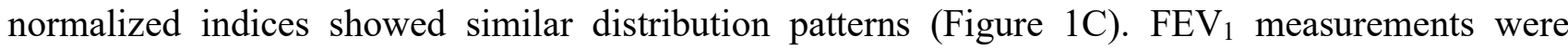
repeated every 6-12 months for 5 years (total 1811 measurements/247 patients), and the annual FEV 1 decline was calculated using a linear mixed-effects model. The study was performed in accordance with the Declaration of Helsinki and approved by the Ethics Committee of Kyoto University (E182 and R0311-2). All participants provided written informed consent.

In total, 247 patients were enrolled from 2006 to 2012 (Table 1). The median follow-up period was 3296 days, and 56 patients died. The mean (SD) FEV 1 decline was -34 (25) ml/year. In Figure 2A, an increase in the LAV\% only was significantly associated with an additional $\mathrm{FEV}_{1}$ decline in univariable linear regression analyses, and an increase in the LAV\% and decreases in the fractal D, TAC, PM $\mathrm{CSA}_{\mathrm{C} A}$ and $\mathrm{ESM}_{\mathrm{CSA}}$ were significantly associated with an increased hazard ratio (HR) for mortality in univariable Cox proportional hazards models. Figure $2 \mathrm{~B}$ shows the results of multivariable linear regression analyses and Cox proportional-hazards models that adjusted for age, sex, body mass index, mMRC dyspnoea scale, $\mathrm{FEV}_{1}$, and diffusion capacity. An increase in the LAV\% was associated with a larger $\mathrm{FEV}_{1}$ decline (additional decline [95\% confidence interval $\left.(95 \% \mathrm{CI})\right]=-2.6 \mathrm{ml} /$ year $[-4.9$, -0.3 ] per $4.65 \%$ increase) compared to the other CT indices, whereas reductions in the ESMCSA were associated with poor prognoses $\left(\mathrm{HR}[95 \% \mathrm{CI}]=1.3[1.1,1.5]\right.$ per $3.67 \mathrm{~cm}^{2}$ reduction), with a stronger relationship than those of the other CT indices.

This is the first report to compare the relative impacts of various chest CT indices on lung function decline and mortality in COPD. The LAV\% had the strongest association with the FEV 1 decline, and the ESM $\mathrm{CSA}_{\text {had }}$ the strongest association with mortality over 10 years after adjusting for clinical variables that are routinely collected in clinical COPD practice.

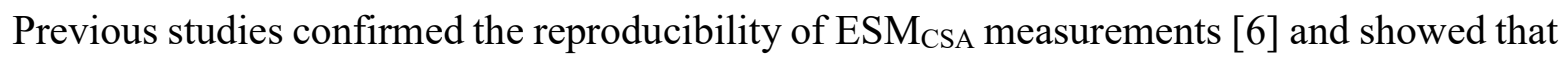
a decreased ESM $\mathrm{CSA}_{\mathrm{C}}$ was associated with increased mortality in COPD patients [9]. The present study extends this by showing that ESM $\mathrm{CSA}_{\mathrm{A}}$ is more strongly associated with mortality than emphysema and 
airway disease when demographics, dyspnoea, and pulmonary function were considered. Since the loss of skeletal muscle mass is a prognostic factor in COPD and the PM $\mathrm{CSA}_{\text {can }}$ reflect the fat-free

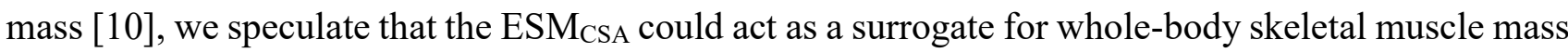
and help predict the prognosis of COPD.

The association between the $\mathrm{LAV} \%$ and $\mathrm{FEV}_{1}$ decline presented here confirms that the emphysematous phenotype of COPD carries a high risk of lung function decline [1]. In contrast, the impact of the LAV\% on mortality was confirmed in the univariable model but disappeared in the multivariable model. This might have been affected by the adjustment for diffusion capacity. However, even when diffusion capacity was excluded from the multivariable model, the ESMCSA still had a stronger association with mortality $\left(\mathrm{HR}[95 \% \mathrm{CI}]=1.30[1.10,1.54]\right.$ per $3.67 \mathrm{~cm}^{2}$ reduction) than the LAV $\%$ did $(\mathrm{HR}[95 \% \mathrm{CI}]=1.20[0.98,1.38]$ per $4.65 \%$ increase $)$. Furthermore, because $\mathrm{FEV}_{1}$ and diffusion capacity can be measured without radiation exposure, the finding that the ESM $\mathrm{CSA}_{\text {a }}$ had the strongest association with mortality independent of pulmonary function is clinically relevant.

The WA\%, TAC, and AWV\% were not associated with $\mathrm{FEV}_{1}$ decline or mortality. This finding is inconsistent with a previous finding showing an association between a lower TAC and a larger $\mathrm{FEV}_{1}$ decline in mild COPD patients [5]. This inconsistency might be due to differences in the inclusion criteria, as the present study included patients with all COPD severities.

This study has limitations. First, we did not assess physical activity, muscle strength or exercise capacity. Second, many patients did not use long-acting bronchodilators (LABDs) because the present study started in 2006. Whether LABDs affect the impact of CT indices on FEV decline $_{1}$ should be further investigated. Third, the small numbers of female subjects and deaths may limit the generalizability of the findings.

In conclusion, the $\mathrm{ESM}_{\mathrm{CSA}}$ is a useful imaging marker that is more closely associated with long-term mortality than emphysema and airway disease when assessing COPD patients using demographics, dyspnoea, pulmonary function, and CT findings. 


\section{References}

1. Vestbo J, Edwards LD, Scanlon PD, Yates JC, Agusti A, Bakke P, Calverley PM, Celli B, Coxson HO, Crim C, Lomas DA, MacNee W, Miller BE, Silverman EK, Tal-Singer R, Wouters E, Rennard SI, Investigators E. Changes in forced expiratory volume in 1 second over time in COPD. N Engl J Med 2011; 365(13): 1184-1192.

2. Haruna A, Muro S, Nakano Y, Ohara T, Hoshino Y, Ogawa E, Hirai T, Niimi A, Nishimura K, Chin K, Mishima M. CT scan findings of emphysema predict mortality in COPD. Chest 2010; 138(3): 635-640.

3. Shimizu K, Tanabe N, Tho NV, Suzuki M, Makita H, Sato S, Muro S, Mishima M, Hirai T, Ogawa E, Nakano Y, Konno S, Nishimura M. Per cent low attenuation volume and fractal dimension of low attenuation clusters on CT predict different long-term outcomes in COPD. Thorax 2020; 75(2): 116-122.

4. Kirby M, Tanabe N, Tan WC, Zhou G, Obeidat M, Hague CJ, Leipsic J, Bourbeau J, Sin DD, Hogg JC, Coxson HO, Can CCRG, Canadian Respiratory Research N, CanCold Collaborative Research Group tCRRN. Total Airway Count on Computed Tomography and the Risk of Chronic Obstructive Pulmonary Disease Progression. Findings from a Population-based Study. Am J Respir Crit Care Med 2018; 197(1): 56-65.

5. Tanabe N, Sato S, Oguma T, Shima H, Sato A, Muro S, Hirai T. Associations of airway tree to lung volume ratio on computed tomography with lung function and symptoms in chronic obstructive pulmonary disease. Respir Res 2019; 20(1): 77.

6. Tanimura K, Sato S, Fuseya Y, Hasegawa K, Uemasu K, Sato A, Oguma T, Hirai T, Mishima M, Muro S. Quantitative Assessment of Erector Spinae Muscles in Patients with Chronic Obstructive Pulmonary Disease. Novel Chest Computed Tomography-derived Index for Prognosis. Ann Am Thorac Soc 2016; 13(3): 334-341.

7. Diaz AA, Martinez CH, Harmouche R, Young TP, McDonald ML, Ross JC, Han ML, Bowler 
R, Make B, Regan EA, Silverman EK, Crapo J, Boriek AM, Kinney GL, Hokanson JE, Estepar RSJ, Washko GR. Pectoralis muscle area and mortality in smokers without airflow obstruction. Respir Res 2018; 19(1): 62 .

8. Waschki B, Kirsten A, Holz O, Muller KC, Meyer T, Watz H, Magnussen H. Physical activity is the strongest predictor of all-cause mortality in patients with COPD: a prospective cohort study. Chest 2011; 140(2): 331-342.

9. Tanimura K, Sato S, Sato A, Tanabe N, Hasegawa K, Uemasu K, Hamakawa Y, Oguma T, Muro S, Hirai T. Accelerated loss of antigravity muscles is associated with mortality in patients with COPD. Respiration 2020; 99: 298-306.

10. McDonald M-LN, Diaz AA, Ross JC, San Jose Estepar R, Zhou L, Regan EA, Eckbo E, Muralidhar N, Come CE, Cho MH, Hersh CP, Lange C, Wouters E, Casaburi RH, Coxson HO, MacNee W, Rennard SI, Lomas DA, Agusti A, Celli BR, Black-Shinn JL, Kinney GL, Lutz SM, Hokanson JE, Silverman EK, Washko GR. Quantitative computed tomography measures of pectoralis muscle area and disease severity in chronic obstructive pulmonary disease. A cross-sectional study. Ann Am Thorac Soc 2014; 11: 326-334. 
Table. Demographics of the study participants

\begin{tabular}{|c|c|}
\hline $\mathrm{N}$ & 247 \\
\hline Age, years & $70.0(8.4)$ \\
\hline Sex (male: female) & 224: 23 \\
\hline Body mass index, $\mathrm{kg} / \mathrm{m}^{2}$ & $22.1(2.9)$ \\
\hline Smoking (pack-years) & $64.8(34.2)$ \\
\hline $\mathrm{FEV}_{1}(\%$ predicted $), \%$ & $61.8(20.8)$ \\
\hline FVC $(\%$ predicted $), \%$ & $93.5(16.7)$ \\
\hline $\mathrm{FEV}_{1} / \mathrm{FVC}, \%$ & $0.51(0.1)$ \\
\hline GOLD spirometric grade $(1 / 2 / 3 / 4)$ & $58 / 111 / 66 / 12$ \\
\hline DLCO $(\%$ predicted $), \%$ & $54.7(20.0)$ \\
\hline $\operatorname{mMRC}(0 / 1 / 2 / 3 / 4)$ & $70 / 115 / 54 / 8$ \\
\hline
\end{tabular}

$\mathrm{FEV}_{1}=$ forced expiratory volume in 1 second, $\mathrm{FVC}=$ forced vital capacity, GOLD $=$ The Global Initiative for Chronic Obstructive Lung Disease. $\mathrm{D}_{\mathrm{LCO}}=$ diffusion capacity for carbon monoxide, mMRC $=$ modified Medical Research Council dyspnoea scale. 


\section{Figure legends}

Figure 1. Two COPD cases with different cross-sectional areas of the erector spinae muscles on

\section{CT and distributions of normalized $\mathrm{CT}$ indices in all 247 cases.}

(A and B) The cross-sectional areas of the erector spinae muscles (ESA $\mathrm{CSA}_{\mathrm{A}}$ ), emphysema and airway indices were measured on CT scans in this study. The ESA $\mathrm{CSA}_{\text {a }}$ was larger in case A than in case B (41.9 vs $21.0 \mathrm{~cm}^{2}$ ). The TAC was also smaller in case A than in case B (178 vs 283), whereas the height (160 vs $163 \mathrm{~cm}), \mathrm{FEV}_{1}(1.12$ vs $1.00 \mathrm{~L}), \mathrm{mMRC}$ score (both 1) and low percentage of attenuation volume (LAV\%, 29.2 vs 29.5\%) did not differ between the two cases. (C) Histogram of each CT index that was normalized by half of a standard deviation (SD). The distribution patterns, represented by the shape and range of histograms, were similar for all the normalized indices. This allowed a comparison of the relative impacts that are associated with a 1-normalized unit change.

Figure 2. Univariable and multivariable analyses to compare the relative impacts of CT indices on lung function decline and mortality in patients with COPD $(\mathrm{n}=\mathbf{2 4 7})$.

(A) Univariable models. (B) Multivariable models that included the CT index, age, sex, body mass index, smoking status, forced expiratory volume in 1 second ( $\%$ of predicted), diffusion capacity for carbon monoxide (\% of predicted), and modified Medical Research Council (mMRC) dyspnoea scale as explanatory variables. Diamonds and lines indicate the estimated magnitude of the association and 95\% confidence interval (CI) for each normalized CT index. 
Fig. 1
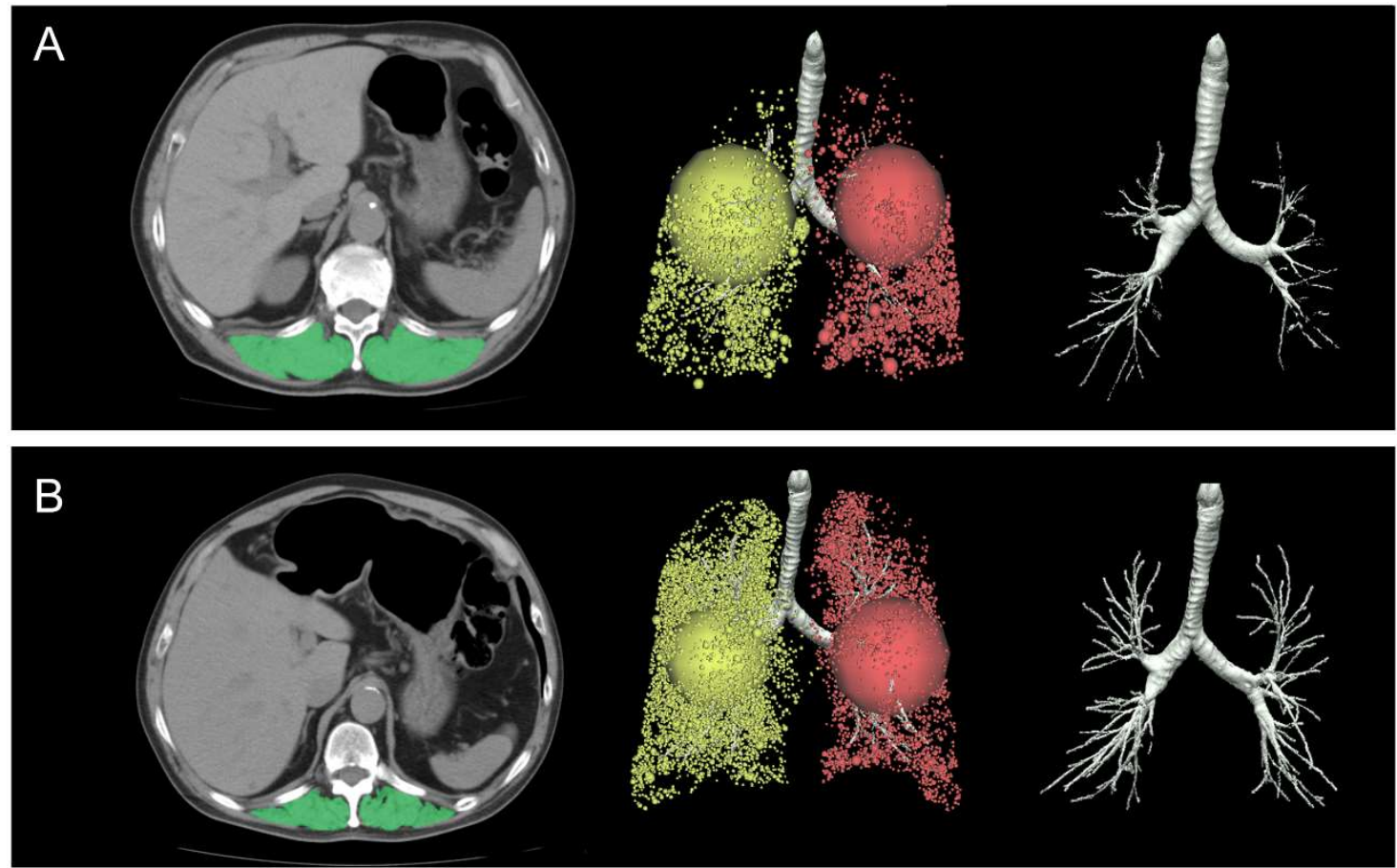

C

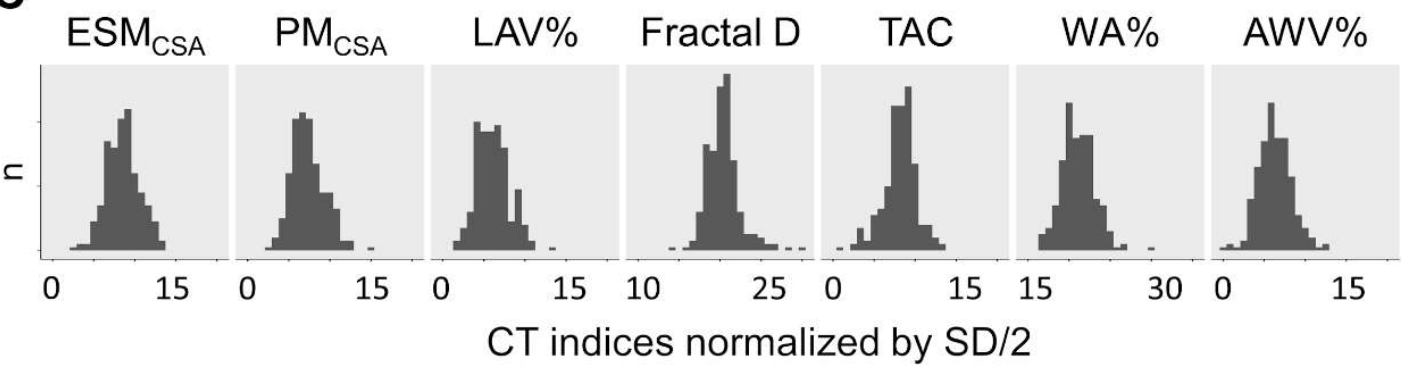


Fig. 2

A

[univariable model]

TAC, per 53.2 decrease

WA $\%$, per $2.8 \%$ increase

AWV\%, per $0.12 \%$ decrease

Fractal D, per 0.06 decrease

LAV\%, per $4.7 \%$ increase

$\mathrm{PM}_{\mathrm{CSA}}$, per $3.7 \mathrm{~cm}^{2}$ decrease

$\mathrm{ESM}_{\mathrm{CSA}}$, per $3.7 \mathrm{~cm}^{2}$ decrease

B

[multivariable model]

TAC, per 53.2 decrease

WA $\%$, per $2.8 \%$ increase

AWV\%, per $0.12 \%$ decrease

Fractal D, per 0.06 decrease

LAV\%, per $4.7 \%$ increase

$\mathrm{PM}_{\mathrm{CSA}}$, per $3.7 \mathrm{~cm}^{2}$ decrease

$\mathrm{ESM}_{\mathrm{CSA}}$, per $3.7 \mathrm{~cm}^{2}$ decrease
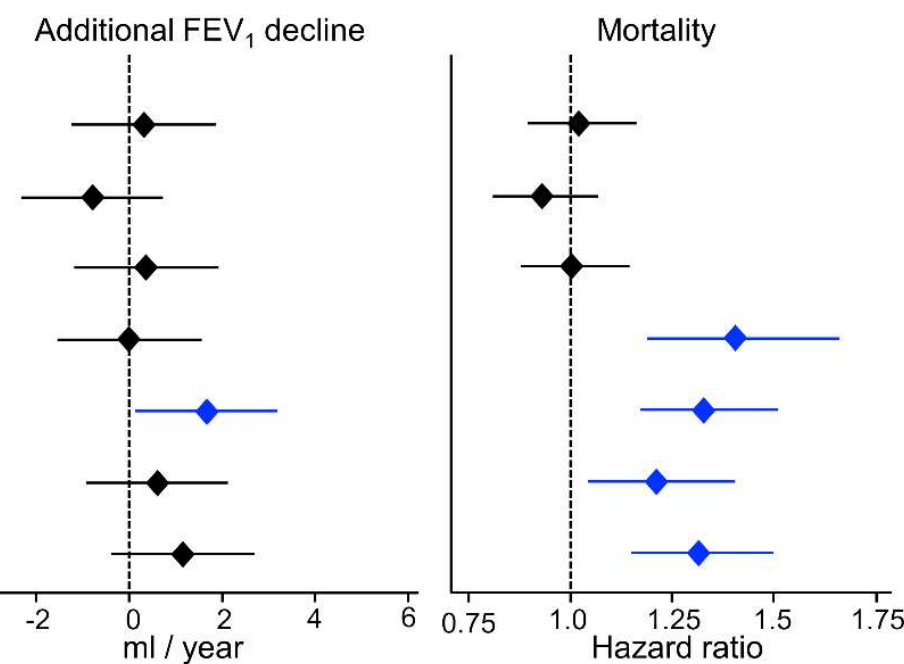

Additional $\mathrm{FEV}_{1}$ decline
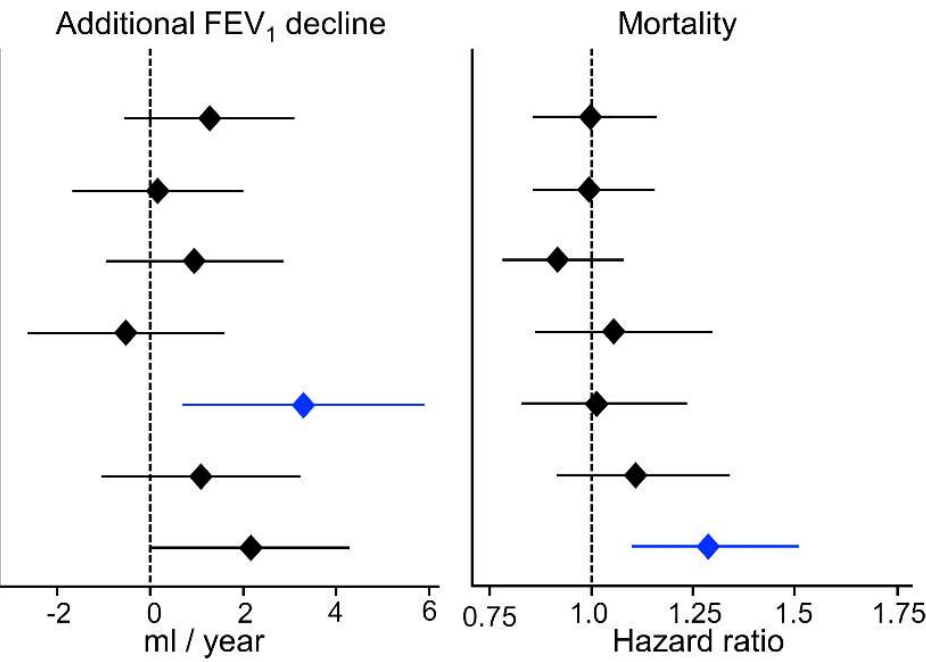